\title{
Suicide risk in Veterans Health Administration patients with mental health diagnoses initiating lithium or valproate: a historical prospective cohort study
}

Eric G Smith ${ }^{1,2^{*}}$, Karen L Austin ${ }^{3,4}$, Hyungjin Myra Kim ${ }^{3,4,5}$, Donald R Miller ${ }^{1,6}$, Susan V Eisen ${ }^{1,6}$, Cindy L Christiansen ${ }^{1,6}$, Amy M Kilbourne ${ }^{3,7,8}$, Brian C Sauer ${ }^{9,10}$, John F McCarthy ${ }^{3,4,8}$ and Marcia Valenstein ${ }^{3,4,8}$

\begin{abstract}
Background: Lithium has been reported in some, but not all, studies to be associated with reduced risks of suicide death or suicidal behavior. The objective of this nonrandomized cohort study was to examine whether lithium was associated with reduced risk of suicide death in comparison to the commonly-used alternative treatment, valproate.

Methods: A propensity score-matched cohort study was conducted of Veterans Health Administration patients ( $n=21,194 /$ treatment) initiating lithium or valproate from 1999-2008.

Results: Matching produced lithium and valproate treatment groups that were highly similar in all 934 propensity score covariates, including indicators of recent suicidal behavior, but recent suicidal ideation was not able to be included. In the few individuals with recently diagnosed suicidal ideation, a significant imbalance existed with suicidal ideation more prevalent at baseline among individuals initiating lithium than valproate (odds ratio (OR) $1.30,95 \% \mathrm{Cl} 1.09,1.54 ; \mathrm{p}=0.003)$. No significant differences in suicide death were observed over 0-365 days in A) the primary intent-to-treat analysis (lithium/valproate conditional odds ratio (cOR) 1.22, 95\% Cl 0.82, 1.81; $\mathrm{p}=0.32$ ); B) during receipt of initial lithium or valproate treatment ( $C O R 0.86,95 \% \mathrm{Cl} 0.46,1.61 ; \mathrm{p}=0.63$ ); or $\mathrm{C}$ ) after such treatment had been discontinued/modified (OR 1.51,95\% Cl 0.91, 2.50; $p=0.11)$. Significantly increased risks of suicide death were observed after the discontinuation/modification of lithium, compared to valproate, treatment over the first 180 days (OR 2.72, 95\% Cl 1.21, 6.11; $\mathrm{p}=0.015)$.

(Continued on next page)
\end{abstract}

\footnotetext{
* Correspondence: Eric.Smith5@va.gov

'Department of Veterans Affairs, Health Services Research \& Development (HSR\&D) Center for Healthcare Organization and Implementation Research (CHOIR), MD-152, ENRM VAMC, 200 Springs Road, Bedford, MA 01730, USA ${ }^{2}$ Department of Psychiatry, University of Massachusetts Medical School, Worcester, MA, USA

Full list of author information is available at the end of the article
} 
(Continued from previous page)

Conclusions: In this somewhat distinct sample (a predominantly male Veteran sample with a broad range of psychiatric diagnoses), no significant differences in associations with suicide death were observed between lithium and valproate treatment over 365 days. The only significant difference was observed over 0-180 days: an increased risk of suicide death, among individuals discontinuing or modifying lithium, compared to valproate, treatment. This difference could reflect risks either related to lithium discontinuation or higher baseline risks among lithium recipients (i.e., confounding) that became more evident when treatment stopped. Our findings therefore support educating patients and providers about possible suicide-related risks of discontinuing lithium even shortly after treatment initiation, and the close monitoring of patients after lithium discontinuation, if feasible. If our findings include residual confounding biasing against lithium, however, as suggested by the differences observed in diagnosed suicidal ideation, then the degree of beneficial reduction in suicide death risk associated with active lithium treatment would be underestimated. Further research is urgently needed, given the lack of interventions against suicide and the uncertainties concerning the degree to which lithium may reduce suicide risk during active treatment, increase risk upon discontinuation, or both.

Keywords: Suicide, Lithium, Valproate, Veterans, Veterans Health Administration, Propensity score, Matching, Discontinuation, Intent-to-treat, Suicidal behavior

\section{Background}

Preventing suicide is a global imperative [1], a need for Veterans [2] (especially those with mental health conditions [3]), and a priority for the Veterans Health Administration (VHA) [4]. The psychiatric medication lithium has been previously reported to be associated with uniquely large reductions in risks of suicide death and suicidal behavior [5-7]. Many studies, however, have been nonrandomized, and a 2013 randomized trial meta-analysis did not note any statistically significant differences in suicide deaths between lithium and specific comparison medications [8]. Despite the inclusion of 35 trials, however, just 4 suicide deaths were observed among patients assigned to lithium and 9 suicide deaths among patients assigned to other medications [8]. In contrast, lithium was associated with a significant, and quite substantial, reduction in suicide death compared to placebo (Odds Ratio (OR) 0.13, 95\% CI 0.03, 0.66, $\mathrm{p}=0.01$ ). A significantly lower risk of suicide death was also noted in a trial of lithium augmentation versus placebo augmentation of antidepressant treatment in major depression, but again was based on extremely few outcomes (3 suicide deaths, all receiving placebo augmentation) [9].

The specific question of whether significant differences in suicide death or suicidal behavior exist between lithium and the anticonvulsant valproate is of particular importance. Valproate is a more commonly-used treatment alternative in the United States than lithium for patients with mood disorders, particularly bipolar disorder. A prominent 2003 nonrandomized study of health maintenance patients with bipolar disorder has only added interest in this comparison by reporting that lithium was associated with statistically significant, $>60 \%$ lower risks of suicide death and suicidal behavior compared to valproate [6]. The 2013 randomized trial meta-analysis, however, was unable to evaluate whether differences between lithium and valproate exist in the risk of suicide death, since no suicide deaths were observed in any of the five trials comparing these medications [8]. The metaanalysis did report nonsignificant differences in suicidal behavior between lithium and valproate (OR 0.64, 95\% CI $0.30,1.36, p=0.24)$. Valproate is, however, one of many antiepileptic medications that now carries a US Food and Drug Administration-mandated warning stating that antiepileptic medications increase the risks of suicidal thoughts or behavior (for patients taking these medications for any indication). We therefore decided to conduct a nonrandomized cohort study of patients with mental health disorders initiating lithium and valproate using the VHA's large and detailed clinical databases.

Nonrandomized studies can provide the large samples needed to more easily determine associations between treatments and suicide-related outcomes (especially suicide death). Many previous nonrandomized studies, however, have suffered from substantial methodological limitations, lacking adjustment for many potential confounders, active controls, incident-user designs, uniform follow-up, or intent-to-treat designs [10]. In particular, concerns exist that previous nonrandomized studies may have been confounded through preferential prescription of lithium to patients at low [11] or lower [10] risk of suicide death. It is possible, however, although unestablished, that prescriber behavior has changed over the past 15 years given wellpublicized meta-analyses [12,13], treatment guidelines [14], and high-profile studies [6] reporting that lithium treatment may be associated with distinct reductions in suicide death or suicidal behavior.

Using data from this more recent period in which the direction of any confounding between lithium and comparison treatments may have changed, we also sought to reduce the amount of any confounding through methods intended to approximate some of the strengths of randomized trials. In 
addition to adopting a fixed follow-up time, these methods included: 1) matching patients based on a propensity score [15] of extensive scope and detail [16], and 2) deriving intent-to-treat and post-discontinuation risk estimates [17]. Propensity score matching can permit a greater number of covariates than previously possible to be controlled, creating treatment groups closely similar in prevalence for numerous covariates (similar, in some respects, to a trial). Intent-to-treat estimates ensure that risks arising after treatment discontinuation are considered in judgments of treatment effectiveness. Combining this more recent data with these methodological approaches, we conducted the largest cohort study to date examining whether the risk of suicide death differs between patients initiated on lithium compared to valproate.

\section{Methods}

\section{Data sources}

Demographic, inpatient and outpatient mental and nonmental health treatment records, and outpatient pharmacy prescription data was obtained from the VHA's National Psychosis and Depression Registries [18] (linked, deidentified healthcare databases of all VHA patients since 1997 with at least one psychotic or depressive disorder diagnosis). This study involved no prospective enrollment of human subjects. Treatment exposure, covariates, and outcome were characterized by information previously recorded during use of the VHA by patients. As with other large healthcare database outcome studies, no informed consent was obtained. This study was approved by the Institutional Review Boards of the Bedford and Ann Arbor Veterans Affairs Medical Centers.

\section{Study cohort}

Incident users ( $>6$ months of no lithium or valproate use) with recent VHA utilization (past year and a previous year) were identified among all patients with mood or psychotic disorders within the past 30 days receiving at least one outpatient prescription for lithium or valproate from April 1999 to December 2008. These broad diagnostic inclusion criteria (Additional file 1: Appendix 1) were chosen to maximize statistical power, given the comparatively few suicides expected, even in a large cohort, over a fixed one-year follow-up period, and to facilitate the evaluation of lithium and valproate as broadly useful suicide preventatives. Prior research suggests that any effectiveness of lithium against suicide death is not restricted to patients with bipolar disorder $[9,19]$. Individuals with potentially nonpsychiatric indications for treatment were excluded (epilepsy, migraine headache, or neuropathy diagnoses in the past 30 days; dementia medication use in the past 180 days; cancer, dementia, skull fracture or traumatic brain injury diagnosis in the past year; traumatic brain injury treatment, home care, or hospice care in the past year; or any nursing home residence or inpatient rehabilitation in the past 2 years). Patients were also excluded if they had started their mood stabilizer on an "as needed" basis (as indicated by receiving an initial prescription designated "prn") or both mood stabilizers simultaneously (Figure 1).

\section{Exposure determination}

Receipt of lithium or valproate was determined by outpatient prescription fills. The primary analysis examined all individuals initiating either lithium or valproate treatment and followed these individuals until end of followup (365 days), suicide death, or death from other causes (i.e., an "intent-to-treat" analysis). As clarification, our study did not examine primary and secondary outcomes per se (the focus consistently being on suicide death), but we did perform primary (intent-to-treat) and secondary analyses of this outcome. Additional secondary analyses examined briefer follow-up times and/or stratified follow-up time by whether individuals were still receiving initial treatment. Individuals were identified as "still receiving initial treatment" if they had not switched to or added the other treatment, nor discontinued the initial treatment (experienced $\mathrm{a} \geq 15$ day gap between outpatient prescriptions, adjusted for early refills). All other follow-up time was classified as occurring during the period when individuals had "stopped/modified" initial treatment. Since this stopper/modifier group included individuals subsequently resuming either treatment, we also analyzed suicide death risks for individuals over 0-180 days which had stopped initial treatment and not resumed either treatment before suicide, other mortality, or the end of follow-up. Risks observed after treatment discontinuation may reflect risks related to discontinuation of the medication (e.g., "rebound" mania or depression), but may also reflect differences in baseline risk between the treatment groups (i.e., confounding) or differences in selection occurring during follow-up [17].

\section{Outcome}

Date and cause of death (suicide) was obtained from $\mathrm{Na}$ tional Death Index files [20] for 1999-2009 using previously established definitions (International Classification of Diseases, Tenth Revision, codes X60-X84, Y87.0, and U03) [21].

\section{Propensity score modeling}

An extensive set of 934 baseline covariates was derived (Table 1 and Additional file 1: Appendix 2) from VHA databases reflecting demographics, diagnoses, general VHA mental and nonmental health healthcare utilization [16], hospitalizations, clinic use, diagnostic testing, current and recent prescriptions (Additional file 1: Appendix 3), 


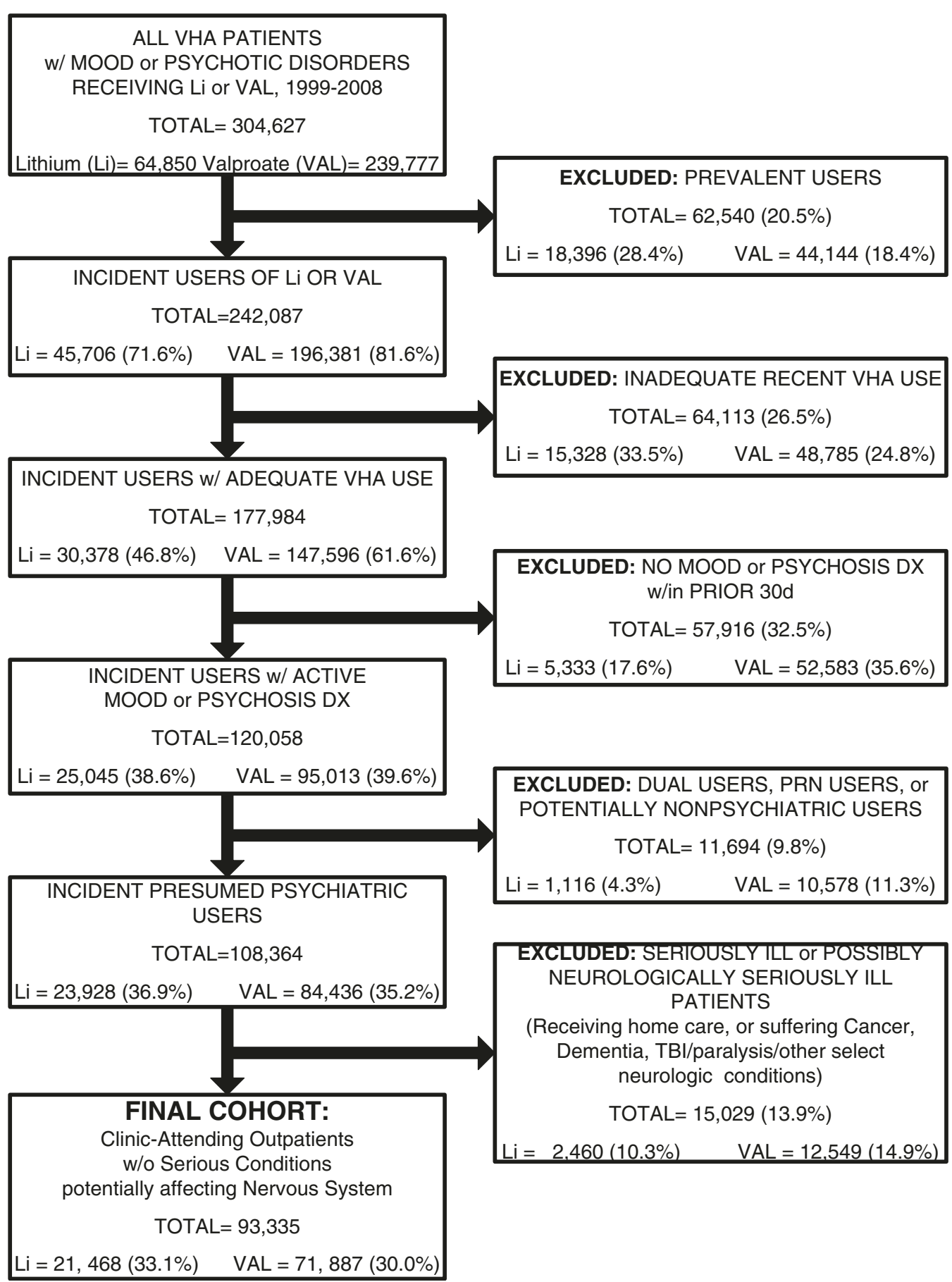

Figure 1 Flowchart of Study Cohort Derivation.

diagnosed suicidal behavior, injuries, regional (statelevel) suicide risk (Additional file 1: Appendix 2), and prior mood stabilizer treatment. Data in these categories were often modeled over several time periods or with flexible forms (multiple indicator variables). This approach follows the general aims of "high-dimensional" propensity score methodology $[16,22]$, but did not include automated variable generation or selection. Instead, a number of covariates in each domain (Table 1) were generally included, since the full determinants of suicide risk are not well understood, although covariates with a substantial association with treatment exposure (i.e., with which treatment a patient receives) were individually evaluated and removed if they were judged 
Table 1 Summary of variables included in the propensity score ${ }^{a}$

\begin{tabular}{|c|c|}
\hline Type of patient characteristic & Covariates included \\
\hline \multicolumn{2}{|r|}{ General Covariates } \\
\hline Demographics & $\begin{array}{l}49 \text { Total Covariates including: Age (5-year categories), Sex, self-reported Race, Ethnicity, Marital Status, } \\
\text { Income, Disability Status, Distance to VHA facility, Urban/Rural hospital location, and Year of Medication Start }\end{array}$ \\
\hline \multicolumn{2}{|r|}{ Psychiatric Covariates $^{\mathbf{b}}$} \\
\hline Presenting Diagnosis & $\begin{array}{l}9 \text { Variables, including Bipolar I, Bipolar II, Bipolar NOS, Major Depression, Depression NOS, Schizophrenia, } \\
\text { Schizoaffective Disorder and Other Psychoses }\end{array}$ \\
\hline General Utilization & $\begin{array}{l}74 \text { Covariates, including Total VHA Mental Health (MH) Provider Visits } \times 6 \text { time periods, Total MH } \\
\text { hospitalizations } \times 2 \text { time periods, and Total Diagnostic Interviews, Total Medication Management Visits, } \\
\text { Total Individual Psychotherapy Visits, Total Group Psychotherapy Visits (all } \times 2 \text { time periods), and Total } \\
\text { Current MH Medications, Recently Discontinued MH medications, and Possibly Discontinued MH medications }\end{array}$ \\
\hline Comorbid Diagnoses & $\begin{array}{l}46 \text { Covariates including PTSD, Other Anxiety Disorders, Adjustment Disorders, Personality Disorders, } \\
\text { Somatoform Disorders, Impulse Control Disorders, Sleep Disorders, Eating Disorders, Sexual Disorders, } \\
\text { Delusional Disorder, ADHD, Development Disorders, Cognitive Disorder NOS, and Dissociative Disorder }\end{array}$ \\
\hline Comorbid Substance Abuse Diagnoses & $\begin{array}{l}41 \text { Covariates, including } 4 \text { Covariates (Abuse, Dependence, Remission from Abuse, and Remission from } \\
\text { Dependence for each of the following: Alcohol, Amphetamines, Cocaine, Marijuana, Opioids, Sedatives, } \\
\text { Other), with other covariates for Hallucinogen Abuse/Dependence/Remission, Combined Drug Dependence } \\
\text { and Remission from Combined Drug Dependence, with and without opioids, Unspecified Dependence, } \\
\text { and Alcohol intoxication and Alcohol or Drug psychoses }\end{array}$ \\
\hline Suicidal Behavior Diagnoses & $\begin{array}{l}9 \text { Covariates, designating if Suicidal Behavior was diagnosed during Nonmental Health hospitalizations, } \\
\text { Mental Health hospitalizations, or as an Outpatient, x } 3 \text { time periods (0-30 days, 31-180 days, or 181-365 } \\
\text { days prior to Lithium or Valproate initiation) }\end{array}$ \\
\hline Psychiatric Hospitalizations & $\begin{array}{l}10 \text { Covariates, including Covariates designating whether patient was an Inpatient on Start Date, } \\
\text { discharged within the last } 7 \text { days, 8-30 days, 31-180 days, and 181-365 days, the type of latest hospitalization } \\
\text { (Psychiatric, Substance Abuse, Residential/Day program, Domiciliary), and whether any hospitalizations in } \\
\text { the last year involved an AMA (Against Medical Advice) discharge }\end{array}$ \\
\hline Specific Outpatient Utilization & $\begin{array}{l}48 \text { Covariates (all modeled as } 0 \text { visits, } 1 \text { visits, or } 2+\text { visits): General Mental Health clinic, Psychiatry visits, } \\
\text { Psychotherapy visits, Substance Use Disorder visit, Primary Care Mental Health clinic, Health Care for } \\
\text { Homeless Veterans, and Substance Abuse and non-Substance Abuse visits, } \times 2 \text { time periods (0-180 days } \\
\text { and 181-365 days) }\end{array}$ \\
\hline Current Medications & $\begin{array}{l}24 \text { Covariates, including Olanzapine, Risperidone, Quetiapine, Ziprasidone, Aripiprazole, Clozapine, First } \\
\text { Generation Antipsychotics, Other Mood Stabilizers, SSRIs, SNRIs, Bupropion, Mirtazapine, TCAs, MAOls, } \\
\text { Benzodiazepines, other Hypnotics, Stimulants, Substance Abuse treatments, and other medications }\end{array}$ \\
\hline Recent Medications & $\begin{array}{l}24 \text { covariates, designating prescriptions received in last } 180 \text { days for same medication categories as } \\
\text { "Current Medications," but for which the patients' prescribed supply does not extend to the Lithium/ } \\
\text { Valproate start date }\end{array}$ \\
\hline Prior Treatment History & Prior treatment with Any Mood Stabilizer, Prior treatment with Lithium or Valproate \\
\hline Geographic Suicide Risk & 5 variables designating quintiles of Age-Adjusted State Suicide Rates (2000-2007) \\
\hline \multicolumn{2}{|r|}{ Nonpsychiatric Variables of Possible Particular Relevance to Suicide Risk ${ }^{\text {b }}$} \\
\hline Nonpsychiatric Diagnoses & $\begin{array}{l}7 \text { covariates, including any Acute Injury, any Fracture, Blood Vessel injury, Internal injuries, Open Wounds, } \\
\text { Poisoning, Inhalation/Drowning/Asphyxiation injury }\end{array}$ \\
\hline Nonpsychiatric Utilization & 6 covariates, including Pain Clinic visits $(0,1,2+) \times 2$ time periods \\
\hline Nonpsychiatric Medications & 4 variables, including current Opiate Pain Medicine, recent Opiate Pain Medicine, and 2 types of overdose antidotes \\
\hline
\end{tabular}

Numerous covariates designating Nonpsychiatric Diagnoses, Nonpsychiatric Hospitalizations, Nonpsychiatric VHA Utilization (both the general amount of Nonpsychiatric VHA care received and specific clinics attended and/or care received ), Nonpsychiatric Medications (current and recent), and Nonpsychiatric Diagnostic Tests.

3 covariates recording prior VHA pharmacy use (any prior use, use in the last 180 days, and use in the last 365 days) were also included to help balance the extensiveness of pharmacy records among recipients.

a Prevalence of each covariate balanced within a standardized difference of $<0.018$ in final matched cohort.

${ }^{b}$ All covariates except Demographics relate to care and/or diagnoses made by providers in the VHA health system.

$\mathrm{ADHD}=$ Attention Deficit Hyperactivity Disorder; AMA = Against Medical Advice; MAOI = Monoamine Oxidase Inhibitor; MH = Mental Health; NOS = "Not Otherwise Specified"; PTSD = Post-Traumatic Stress Disorder; SNRI = Serotonin-Norepinephrine Reuptake Inhibitor; SSRI = Serotonin-Specific Reuptake Inhibitor; TCA = Tricyclic Antidepressant; VHA = Veterans Health Administration.

unlikely to be confounders. (Inclusion of variables that are substantially associated with treatment exposure, but which are not confounders, can actually increase confounding from uncontrolled confounders) [23-26].

\section{Statistical methods}

The propensity score was calculated by logistic regression $(\mathrm{c}$ statistic $=0.69)$. We then 1:1 matched patients initiating lithium and valproate using propensity score 
calipers of 0.03 (0.2 standard deviations of the propensity score logit) [27,28], achieving $98.7 \%$ matching of lithium-initiated patients. Balance in the prevalence of covariates between the treatment groups was assessed using standardized differences (Table 2). Standardized differences are equivalent to Cohen's $d$ effect sizes, with a difference of $\geq 0.10$ often considered as indicating significant imbalance [15].

For the analyses of the intent-to-treat cohort and of individuals still receiving initial treatment, we used conditional logistic regression, whereas for individuals stopping or modifying treatment, ordinary logistic regression was used since matching was not rigorously preserved.

Several additional analyses were conducted, including comparing the prevalence between the treatment groups of diagnostically-coded suicidal ideation (V62.84, a code for suicidal ideation first introduced in 2005) in the 30 days prior to treatment initiation among the patients who potentially could receive this diagnosis (the $<50 \%$ of the sample initiating treatment in 2005 or later). We also compared the suicide risk associated with the treatment groups prior to matching, conducted a Cox regression analysis, and conducted a sensitivity analysis matching the sample with an alternative propensity score. All analyses were performed using SAS, version 9.3, except the standardized difference calculations (Microsoft Excel 2007).

\section{Results}

A 1:1 propensity-score matched cohort of 42,388 patients (including 102 suicide deaths over 365 days of follow-up) was derived from 93,335 incident users of lithium or valproate (Figure 1). Patients initiating lithium and valproate were generally balanced even prior to matching on a wide variety of psychiatric and nonpsychiatric diagnoses, outpatient and inpatient utilization, and medication covariates: only 17 of 934 covariates $(1.8 \%)$ exhibited initial standardized differences of $\geq 0.10$ between treatment groups. Table 2 demonstrates the close balance achieved after propensity score matching between treatment groups for these 17 initiallyimbalanced covariates (i.e., the italicized covariates in Table 2) and 14 other important covariates. Similarly close balance after matching was observed for all other covariates (none of the 934 covariates had a standardized difference of even 0.018 after matching). Despite the general balance in most covariates observed between the treatment groups even prior to matching, propensity score matching led to a substantial reduction in the observed treatment effect estimate (initial 0-365 day Odds Ratio $[\mathrm{OR}]=1.45$ [lithium/valproate], versus $0-365$ day Conditional Odds Ratio $[\mathrm{cOR}]=1.22$ after propensity score matching) (Additional file 1: Appendix 4).

The treatment groups also displayed very substantial, but highly similar, rates of stopping or modifying initial treatment: $47 \%$ of patients initiated on both lithium and valproate were still receiving their initial treatment at 90 days, $24 \%$ at 180 days, and only $8 \%$ at 365 days (Additional file 1: Appendix Table S1).

Table 3A and 3B provides results for these extensivelymatched treatment groups over the first year after medication initiation. No significant difference in suicide death was noted in the primary analysis of all patients initiating lithium versus valproate (intent-to-treat 0-365 day cOR 1.22, 95\% Confidence Interval $[\mathrm{CI}]$ 0.82, 1.81; $\mathrm{p}=0.32$ ). In addition, no significant difference was noted in a secondary analysis among patients during the period within the first year in which they were still receiving initial treatment (cOR 0.86, 95\% CI 0.46, 1.61; $\mathrm{p}=0.63$ ), nor among patients once they had stopped or modified lithium, compared to valproate, treatment (OR 1.51, 95\% CI $0.91,2.50 ; \mathrm{p}=0.11$ ).

Secondary analyses of briefer treatment intervals (Table 4A and 4B) indicated an increased intent-to-treat risk of suicide death among all patients initiating lithium over 0-180 days that bordered upon, but did not quite attain, statistically significance (cOR $1.56,95 \%$ CI 0.94 , 2.58; $\mathrm{p}=0.08$ ), in association with significantly elevated risk of suicide death among patients after stopping or modifying lithium, compared to valproate, treatment (OR $2.72,95 \% \mathrm{CI} 1.21,6.11 ; \mathrm{p}=0.015)$. This differing risk of suicide death between individuals stopping/modifying lithium, versus stopping/modifying valproate, treatment over $0-180$ days was associated almost exclusively with those individuals stopping, rather than modifying, treatment (Table 4, Footnote i: OR 3.61, 95\% CI 1.34, 9.73; p = 0.011).

Figure 2 presents the intent-to-treat survival curve for suicide death for the lithium and valproate treatment groups. Because of nonproportional hazards (the crossing of the survival curves at approximately 90 days), the interpretation of the survival analysis is less straightforward than, but generally consistent with, the logistic regression results (Additional file 1: Appendix 5).

Table 5 indicates that recent suicidal ideation, when recorded by diagnostic code, was significantly more prevalent among patients initiating lithium than among those initiating valproate (OR 1.30, 95\% CI 1.09, 1.54; $\mathrm{p}=0.003)$, for the 19,411 patients for whom these data were available.

\section{Discussion}

This manuscript reports the largest study, to our knowledge, examining lithium's association with the risk of suicide death. This study is also first to use two design elements (propensity score matching and intent-to-treat analysis) intended to help nonrandomized studies better approximate findings from randomized trials. In this somewhat distinct sample (a predominantly male Veteran sample with a broad range of psychiatric diagnoses), no significant differences in suicide death were observed 
Table 2 Characteristics of Patients Initiating Lithium and Valproate (Propensity-score Matched Sample)

\begin{tabular}{|c|c|c|c|c|c|}
\hline \multirow[t]{2}{*}{ Patient characteristic } & \multicolumn{2}{|c|}{ Lithium ( $n=21194)$} & \multicolumn{2}{|c|}{ Valproate $(n=21194)$} & \multirow{2}{*}{$\begin{array}{l}\text { Standardizec } \\
\text { difference }\end{array}$} \\
\hline & $\mathbf{N}$ & $(\%)$ & $\mathrm{N}$ & $(\%)$ & \\
\hline \multicolumn{6}{|c|}{ Demographics } \\
\hline Age $\geq 50$ years old ${ }^{a}$ & 10244 & 48.3 & 10156 & 47.9 & 0.008 \\
\hline Sex $(\text { Female })^{\mathrm{b}, \mathrm{c}}$ & 2894 & 13.7 & 2934 & 13.8 & 0.005 \\
\hline Race, White ${ }^{b}$ & 16748 & 79.0 & 16793 & 79.2 & 0.005 \\
\hline Race, Black ${ }^{\mathrm{b}}$ & 2825 & 13.3 & 2770 & 13.1 & 0.008 \\
\hline Married & 7416 & 35.0 & 7298 & 34.4 & 0.012 \\
\hline State Suicide Rate, $3^{\text {rd }}$ quintile $e^{b}$ & 3305 & 15.6 & 3251 & 15.3 & 0.007 \\
\hline \multicolumn{6}{|c|}{ Presenting Diagnosis $^{\mathbf{d}}$ (Past 30 days) } \\
\hline Bipolar / Disorder ${ }^{b}$ & 9562 & 45.1 & 9683 & 45.7 & 0.011 \\
\hline Bipolar Disorder, & 1643 & 7.8 & 1661 & 7.8 & 0.003 \\
\hline \multicolumn{6}{|l|}{ Not Otherwise Specified (NOS) } \\
\hline Depressive Disorder, & 4214 & 19.9 & 4129 & 19.5 & 0.010 \\
\hline \multicolumn{6}{|l|}{ Not Otherwise Specified (NOS) ${ }^{b}$} \\
\hline Schizophrenia ${ }^{\mathrm{b}}$ & 924 & 4.4 & 949 & 4.5 & 0.006 \\
\hline Other Psychosis ${ }^{\mathrm{b}}$ & 252 & 1.2 & 255 & 1.2 & 0.001 \\
\hline \multicolumn{6}{|c|}{ Additional Psychiatric Diagnoses (Past Year) } \\
\hline Post-Traumatic Stress Disorder (PTSD) $)^{b}$ & 4842 & 22.8 & 4749 & 22.4 & 0.010 \\
\hline Alcohol Dependence & 4426 & 20.9 & 4478 & 21.1 & 0.006 \\
\hline \multicolumn{6}{|c|}{ Recent Suicidal Behavior Diagnoses (past 30d, by location where diagnosed) } \\
\hline Nonmental Health Hospital-Diagnosed & 28 & 0.13 & 24 & 0.11 & 0.005 \\
\hline Mental Health Hospital-Diagnosed & 30 & 0.14 & 32 & 0.15 & 0.002 \\
\hline Outpatient Visit-Diagnosed & 144 & 0.68 & 147 & 0.69 & 0.002 \\
\hline \multicolumn{6}{|c|}{ Recent Suicidal Behavior Diagnoses (past 31-180d, by location where diagnosed) } \\
\hline Nonmental Health Hospital-Diagnosed & 43 & 0.20 & 43 & 0.20 & 0.000 \\
\hline Mental Health Hospital-Diagnosed & 31 & 0.15 & 29 & 0.14 & 0.003 \\
\hline Outpatient Visit-Diagnosed & 90 & 0.42 & 82 & 0.39 & 0.006 \\
\hline \multicolumn{6}{|c|}{ Possible Suicidal Behavior-Related Diagnoses (past year) } \\
\hline Any Acute Injury & 3872 & 18.3 & 3884 & 18.3 & 0.001 \\
\hline \multicolumn{6}{|c|}{ Recent Discharge from Psychiatric Hospitalization } \\
\hline Discharged in past 7 days & 2232 & 10.5 & 2219 & 10.5 & 0.002 \\
\hline Discharged in past 8-30 days & 863 & 4.1 & 881 & 4.2 & 0.004 \\
\hline Discharged in past $31-180$ days & 2024 & 9.5 & 2063 & 9.7 & 0.006 \\
\hline \multicolumn{6}{|c|}{ Current Psychiatric Medications } \\
\hline Other Mood Stabilizer(s) & 2891 & 13.6 & 2854 & 13.5 & 0.005 \\
\hline SSRI antidepressant & 7615 & 35.9 & 7666 & 36.2 & 0.005 \\
\hline SNRI antidepressant & 1988 & 9.4 & 2019 & 9.5 & 0.005 \\
\hline \multicolumn{6}{|c|}{ Past Treatment History } \\
\hline Prior Mood Stabilizer & 7503 & 35.4 & 7530 & 35.5 & 0.003 \\
\hline \multicolumn{6}{|c|}{ Diagnoses, Nonpsychiatric (past year) } \\
\hline Mild Liver Disease ${ }^{b}$ & 1747 & 8.2 & 1719 & 8.1 & 0.005 \\
\hline \multicolumn{6}{|c|}{ Outpatient Utilization, Nonpsychiatric (past 180d) } \\
\hline 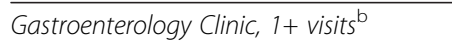 & 1102 & 5.2 & 1077 & 5.1 & 0.005 \\
\hline
\end{tabular}


Table 2 Characteristics of Patients Initiating Lithium and Valproate (Propensity-score Matched Sample) (Continued)

\begin{tabular}{llllrr}
\hline \multicolumn{5}{c}{ Current Medications, Nonpsychiatric } \\
\hline Thiazide Diuretic $^{\mathrm{b}}$ & 1499 & 7.1 & 1492 & 7.0 & 0.001 \\
ACE Inhibitor $^{\mathrm{b}}$ & 2764 & 13.0 & 2736 & 12.9 & 0.004 \\
NSAIDs $^{\mathrm{b}}$ & 3491 & 16.5 & 3522 & 16.6 & 0.004 \\
\hline
\end{tabular}

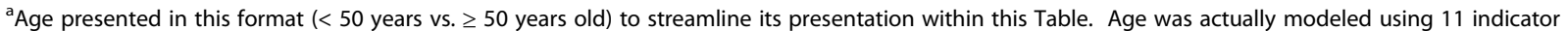
variables reflecting age groups from $<35$ years old, in 5 -year intervals, to $\geq 80$ years old.

${ }^{\mathrm{b}}$ This covariate (designated by italics as well as this footnote) had an initial imbalance between the treatment groups of a standardized difference of $\geq 0.10$. Please see Additional file 1: Appendix 2, Table S1 if more detail is desired.

'The proportion of females in the cohort is low because the Veteran sample is predominantly male.

dPercentages for Indicating Diagnoses do not add up to $100 \%$. Some diagnoses were not substantially imbalanced and therefore not included in the Table, although they were included in the propensity score and matched upon (e.g. Major Depression, Bipolar II Disorder, Schizoaffective Disorder, and $\geq 2$ Indicating Diagnoses in past 30 days).

between lithium and valproate treatment over 0-365 days. This lack of association was observed for both the primary intent-to-treat analyses and for secondary analyses of patients actively receiving their initial treatment (an effectiveness measure traditionally reported in many nonrandomized studies of lithium).

This study's findings diverge from those of some past meta-analyses $[7,29]$, especially those including nonrandomized studies [7]. Several potential reasons suggest themselves. First, follow-up was only continued for one year (some studies have specifically reported that treatment with lithium for greater than one year was required to observe significant reductions in suicide risk [30-32]). A second reason may relate to characteristics of this sample, including its high rates of treatment discontinuation. High rates of treatment discontinuation would be expected to be especially influential in an intent-to-treat design, since effect estimates would substantially reflect risks observed during periods of nonexposure after discontinuation of treatment. Furthermore, in naturalistic studies high rates of discontinuation can complicate the interpretation of risks even among patients apparently receiving active treatment, since it cannot be clearly ascertained whether or when patients prescribed medication actually consume it. Outcomes for patients who do not start a received prescription or terminate it early may be ascribed to active treatment, but actually relate to nonexposure or treatment discontinuation. Alternatively, some prior studies reporting large associations between lithium treatment and reduced suicide risk may have been biased by inadequately controlled initial confounding or differences in selection occurring during treatment $[10,11]$.

However, two other possibilities deserve consideration, since they are consistent with important elements of our data and would have implications for patients, providers, and healthcare systems. Both relate to the statistically significantly increased suicide risks observed among patients discontinuing lithium at 0-180 days. Risks among patients discontinuing treatment may result from several causes, including: 1) genuine new risks produced by medication discontinuation; and 2) non-treatment-related differences in inherent suicide risk between the treatment groups (i.e., baseline confounding not resolved by the propensity score matching). A third potential cause, differing tendencies between the treatment groups for high-risk patients to discontinue treatment (through self- or provider-based selection), may also contribute to these risks but appears less likely to explain the entirety of our findings (Additional file 1: Appendix 6A). If risks observed after lithium discontinuation relate directly to discontinuing lithium, this finding would appear consistent with a substantial literature documenting pronounced suicide risks upon lithium discontinuation (e.g., suicide rates up to 14-fold greater than during the preceding lithium treatment) $[11,12,33]$. However, most of these studies lacked control groups. The only prior study comparing suicidal behavior risks among patients discontinuing lithium or discontinuing valproate observed significant increases in suicidal behavior and/or hospitalization risks among patients discontinuing either treatment [34]. In our study, increased risks of suicide death were observed upon discontinuation of lithium, but not valproate.

The substantial increased risks of suicide death observed among patients discontinuing lithium over $0-180$ days could also reflect potential confounding remaining after propensity score matching $[17,35]$ (i.e., patients initiating lithium being at higher inherent suicide risk). If active lithium treatment was associated with reduced risk of suicide death, then those reduced risks might largely counterbalance confounding in the intent-totreat cohort and among those patients still receiving initial treatment. Such confounding might then most clearly manifest as higher suicide risks among lithiuminitiating, compared to valproate-initiating patients, after treatment discontinuation.

It is unclear whether much confounding persists in our analysis, given the approximate initial balance observed in numerous measured factors and the further balance achieved after propensity score matching. Several lines of evidence suggest, however, that if any substantial confounding does exist, it likely biases against 
Table 3 Suicide deaths and rates over time by mood stabilizer treatment

A. Primary Analysis (Intent-to-treat, 0-365 days)

All Patients Initiating Treatment (Intent-to-Treat Cohort)

\begin{tabular}{llccccccc} 
& \multicolumn{4}{c}{ Patients Initiating Lithium } & \multicolumn{3}{c}{ Patients Initiating Valproate } & \\
\cline { 2 - 6 } Follow-up & Patients, & Suicide & Rate (per 10 & Patients, & Suicide & Rate (per 10 & Conditional Odds Ratio & Rate \\
Time & No. & Deaths, No. & person-days) & No. & Deaths, No. & person-days) & $(95 \%$ Cl) & Ratio \\
0-365 days & 21194 & 56 & 7.27 & 21194 & 46 & 5.98 & $1.22^{\mathrm{a}}(0.82-1.81)$ \\
\hline
\end{tabular}

B. Findings Stratified by Initial Treatment Status (0-365 days)

During Exposure to Initial Treatment ${ }^{\mathrm{b}}$

\begin{tabular}{llccccccc} 
& \multicolumn{3}{c}{ Patients Initiating Lithium } & \multicolumn{3}{c}{ Patients Initiating Valproate } & \\
\cline { 2 - 6 } Follow-up & Patients, & Suicide & Rate (per 10 & Patients, & Suicide & Rate (per 10 & Conditional Odds Ratio & Rate \\
Time & No. & Deaths, No. & person-days) & No. & Deaths, No. & person-days) & $(95 \%$ Cl) & Ratio \\
0-365 days & 21194 & 18 & 6.71 & 21194 & 21 & 7.68 & $0.86^{c}(0.46-1.61)$ & 0.87 \\
\hline
\end{tabular}

During Period After Stopping/Modifying Initial Treatment ${ }^{d}$

\begin{tabular}{|c|c|c|c|c|c|c|c|c|}
\hline \multirow[b]{2}{*}{$\begin{array}{l}\text { Follow-up } \\
\text { Time }\end{array}$} & \multicolumn{3}{|c|}{ Patients Initiating Lithium } & \multicolumn{3}{|c|}{ Patients Initiating Valproate } & \multirow[b]{2}{*}{ Odds Ratio (95\% Cl) } & \multirow[b]{2}{*}{$\begin{array}{l}\text { Rate } \\
\text { Ratic }\end{array}$} \\
\hline & $\begin{array}{l}\text { Patients, } \\
\text { No. }\end{array}$ & $\begin{array}{l}\text { Suicide } \\
\text { Deaths, No. }\end{array}$ & $\begin{array}{l}\text { Rate (per } 10^{6} \\
\text { person-days) }\end{array}$ & $\begin{array}{l}\text { Patients, } \\
\text { No. }\end{array}$ & $\begin{array}{l}\text { Suicide } \\
\text { Deaths, No. }\end{array}$ & $\begin{array}{l}\text { Rate (per } 10^{6} \\
\text { person-days) }\end{array}$ & & \\
\hline 0-365 days & 19494 & 38 & 7.58 & 19362 & 25 & 5.05 & $1.51^{\mathrm{e}}(0.91-2.50)$ & 1.50 \\
\hline
\end{tabular}

${ }^{a} p=0.32$.

bThe counts of patients "During Exposure to Initial Treatment" include all the propensity score-matched patients, since all patients accrued at least some follow-up time in that status. Counts of suicide deaths among these patients indicate suicide deaths occurring on a day in which the patient was classified as still receiving initial treatment. That is, these counts represent suicide deaths occurring during the period covered by a prescribed supply of medication (without any co-prescription of the other medication), or during the gap(s) permitted after the prescription had ended, up until the day that the first gap of 15 or more days had occurred.

$c_{p}=0.63$.

dThe counts of patients "During Period After Stopping/Modifying Initial Treatment" indicates all the patients who reach that status by the end of the follow-up period, since all such patients accrued at least some follow-up time during which they were not still receiving their initially assigned treatment. That is, this is a count of patients modifying their initial treatment by switching to or augmenting with the other medication or discontinuing their initial treatment, either temporarily or permanently. Counts of suicide deaths among these patients among these patients indicate suicide deaths occurring on a day after the patient had exited "During Exposure to Initial Treatment" status, whether by discontinuing or modifying their initial treatment. $\mathrm{e}_{\mathrm{p}}=0.11$.

observing a protective association for lithium. The effect of further increasing covariate balance through propensity score matching was to noticeably reduce initial effect estimates associating lithium with increased suicide death risk. This suggests the initial imbalances in propensity score covariates, although generally small, had the overall effect of biasing associations towards observing higher risks for lithium treatment. Any residual (i.e., remaining) confounding might plausibly bias in the same direction, although this cannot be confirmed with certainty. This bias towards overestimating lithium's hazards, to the degree it is present, might arise from the patients initiating lithium having more severe mental illness in general, or having a greater prevalence or severity of risk factors for suicide death in particular. Of note, while our data is extensive, it does not include information on several important risk factors for suicide death (e.g., suicidal planning, means, recent stressors, and psychiatric symptoms, and, for some individuals, information on suicidal ideation). Our analysis of diagnostically-coded suicidal ideation found modest but significantly higher rates among patients initiating lithium, even after the propensity score matching. This observation is consistent with the possibility that some degree of remaining confounding exists, biasing towards an overestimate of the risks of suicide death associated with lithium.

A role for chance is also important to consider in interpreting our findings, since a substantial number of comparisons were examined and only three statistically significant associations were observed: among patients discontinuing lithium compared to valproate over $0-180$ days (Table 4B), among all patients initiating lithium compared to valproate from 91-180 days, and among patients discontinuing lithium compared to valproate over 91-180 days (Additional file 1: Appendix 5). Nevertheless, while our primary findings over $0-365$ days indicate no statistically significant differences between the treatments, results from even a study of this size do not preclude potentially clinically meaningful differences existing between the treatments below the power of this study to detect. Furthermore, the significant risks in patients discontinuing initial lithium treatment over 0-180 days, if not due to chance, generally suggest some degree of nonequivalency between the treatments. These discontinuation-associated risks suggest that lithium is associated with either or both of the following: higher 
Table 4 Suicide deaths and rates over time by mood stabilizer treatment over briefer time periods (0-90 and 0-180 days) A. Intent-to-Treat Analyses

All Patients Initiating Treatment (Intent-to-Treat Cohort)

\begin{tabular}{|c|c|c|c|c|c|c|c|c|}
\hline \multirow[b]{2}{*}{ Follow-up Time } & \multicolumn{3}{|c|}{ Patients Initiating Lithium } & \multicolumn{3}{|c|}{ Patients Initiating Valproate } & \multirow[b]{2}{*}{$\begin{array}{l}\text { Conditional Odds } \\
\text { Ratio }(95 \% \mathrm{Cl})\end{array}$} & \multirow[b]{2}{*}{ Rate Ratio } \\
\hline & Patients, No. & Suicide Deaths, No. & $\begin{array}{l}\text { Rate (per } 10^{6} \\
\text { person-days) }\end{array}$ & Patients, No. & Suicide Deaths, No. & $\begin{array}{l}\text { Rate (per } 10^{6} \\
\text { person-days) }\end{array}$ & & \\
\hline 0-90 days & 21194 & 18 & 9.35 & 21194 & 19 & 9.87 & $0.95^{\mathrm{a}}(0.50-1.81)$ & 0.95 \\
\hline 0-180 days & 21194 & 39 & 10.20 & 21194 & 25 & 6.54 & $1.56^{\mathrm{b}}(0.94-2.58)$ & 1.56 \\
\hline
\end{tabular}

B. Findings Stratified by Initial Treatment Status

During Exposure to Initial Treatment ${ }^{c}$

\begin{tabular}{|c|c|c|c|c|c|c|c|c|}
\hline \multirow[b]{2}{*}{ Follow-up Time } & \multicolumn{3}{|c|}{ Patients Initiating Lithium } & \multicolumn{3}{|c|}{ Patients Initiating Valproate } & \multirow[b]{2}{*}{$\begin{array}{l}\text { Conditional Odds } \\
\text { Ratio }(95 \% \mathrm{Cl})\end{array}$} & \multirow[b]{2}{*}{ Rate Ratio } \\
\hline & Patients, No. & Suicide Deaths, No. & $\begin{array}{l}\text { Rate (per } 10^{6} \\
\text { person-days) }\end{array}$ & Patients, No. & Suicide Deaths, No. & $\begin{array}{l}\text { Rate (per } 10^{6} \\
\text { person-days) }\end{array}$ & & \\
\hline 0-90 days & 21194 & 15 & 10.00 & 21194 & 17 & 11.30 & $0.88^{d}(0.44-1.77)$ & 0.88 \\
\hline 0-180 days & 21194 & 17 & 7.99 & 21194 & 17 & 7.93 & $1.00^{e}(0.51-1.96)$ & 1.01 \\
\hline
\end{tabular}

During Period After Stopping/Modifying Initial Treatment

\begin{tabular}{|c|c|c|c|c|c|c|c|c|}
\hline \multirow[b]{2}{*}{ Follow-up Time } & \multicolumn{3}{|c|}{ Patients Initiating Lithium } & \multicolumn{3}{|c|}{ Patients Initiating Valproate } & \multirow[b]{2}{*}{ Odds Ratio (95\% Cl) } & \multirow[b]{2}{*}{ Rate Ratio } \\
\hline & Patients, No. & Suicide Deaths, No. & $\begin{array}{l}\text { Rate (per } 10^{6} \\
\text { person-days) }\end{array}$ & Patients, No. & Suicide Deaths, No. & $\begin{array}{l}\text { Rate (per } 10^{6} \\
\text { person-days) }\end{array}$ & & \\
\hline 0-90 days & 11227 & 3 & 6.98 & 11185 & 2 & 4.75 & $1.49^{9}(0.25-8.95)$ & 1.47 \\
\hline 0-180 days & 16138 & 22 & 13.00 & 15958 & 8 & 4.78 & $2.72^{h, i}(1.21-6.11)$ & 2.72 \\
\hline
\end{tabular}

$a_{p}=0.87$.

$\mathrm{b}_{\mathrm{p}}=0.08$.

'See Table 3, Footnote b.

${ }^{d} p=0.72$.

e $p>0.99$.

fSee Table 3, Footnote d.

${ }^{\mathrm{g}} \mathrm{p}=0.66$.

$h_{p}=0.015$.

'Risks observed in patients stopping or modifying initial treatment were almost exclusively observed in patients stopping treatment (rather than modifying

treatment or discontinuing and later resuming either treatment):

Patients Stopping Lithium: Suicides $=18$; Suicide Rate (per $10^{6}$ person-days) $=18.3$.

Patients Stopping Valproate: Suicides $=5$; Suicide Rate (per $10^{6}$ person-days) $=5.09$.

This yields an odds ratio of $3.61(95 \% \mathrm{Cl} 1.34,9.73)$ and a rate ratio of 3.60 .

risks of suicide death for some period after discontinuation (in contrast to the discontinuation of valproate), and/or (if some or all of the risks associated with lithium discontinuation reflect baseline confounding) with greater positive benefits against suicide death than suggested by our findings.

\section{Additional strengths and limitations}

Several study limitations should be noted. Data limitations include gaps in VHA prescription records for inpatients and a lack of information about inpatient and outpatient care received outside the VHA, and potential errors in the measurement of covariates. Analytic limitations included the absence of rematching/reweighting of patients during follow-up. This limitation precluded analysis of whether patients experiencing suicidal ideation or behavior during treatment were preferentially discontinued off one of the two treatments, and of whether differences existed during follow-up between the treatment groups in either the initiation of, or persistence with, other psychiatric medications. This study examined typical care, rather than being restricted to monotherapy, unlike some recent studies [34,36]. Given that other psychiatric medications may influence the risks of suicide death [37,38], future studies should consider approaches which reweight patients during follow-up, such as marginal structural models (Additional file 1: Appendices 6A and 8). However, numerous classes of psychiatric medications prescribed at and before lithium or valproate initiation were very closely balanced between the two treatment groups, thus likely producing close similarity in concomitant medications, at least early during follow-up.

In addition, serum medication levels would provide information separate from prescription data about medication persistence, and might enhance future analyses if available. Study findings might have been influenced by the considerable diagnostic heterogeneity of this patient cohort, although each individual diagnosis was closely balanced in prevalence among lithium and valproate recipients and almost $90 \%$ of our sample had mood 


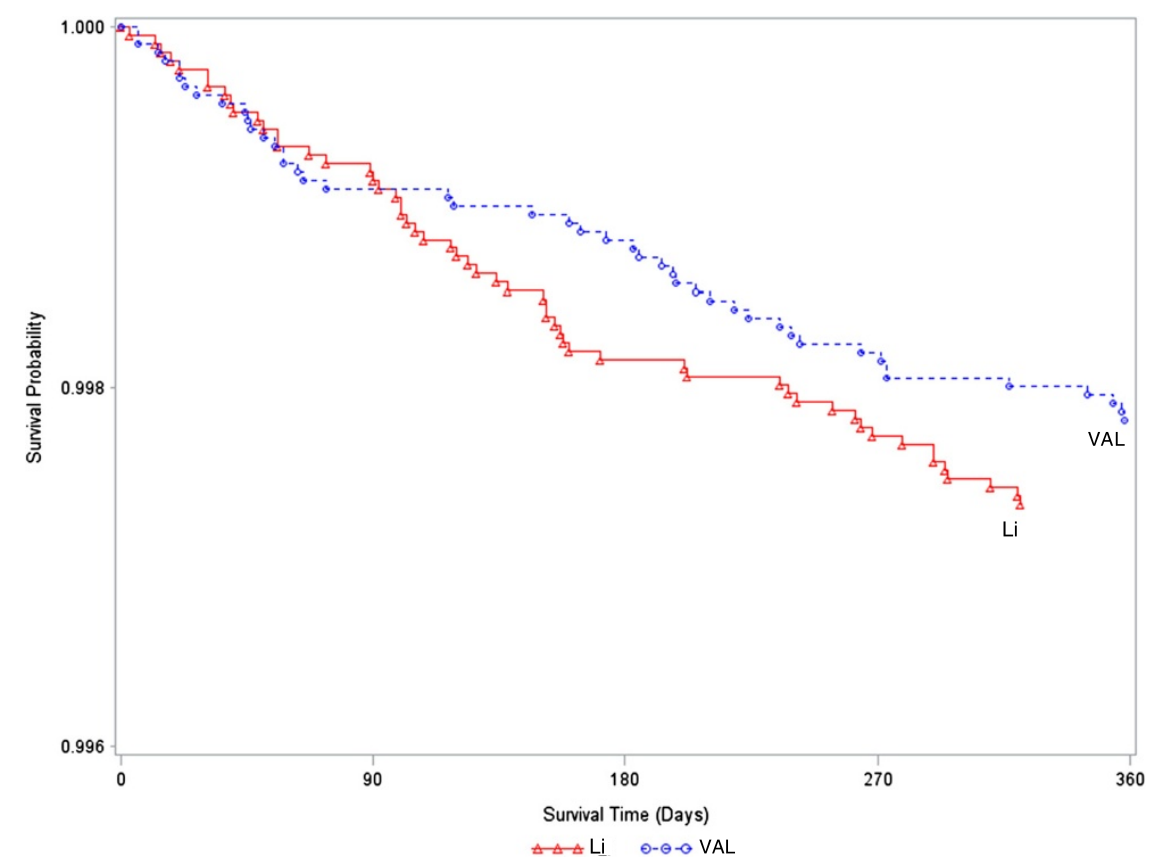

Figure 2 365-day Survival curve of suicide death by treatment (Intent-to-Treat Analysis).

disorder diagnoses (Additional file 1: Appendix 1). Our focus upon suicide mortality (comprehensively documented nationwide, even for patients who leave VHA care) improved outcome ascertainment compared to nonfatal suicidal behavior, but unfortunately limited statistical power. This difference in outcome ascertainment can be substantial: separate studies have estimated that diagnosed nonfatal suicidal behavior may underestimate actual nonfatal suicidal behavior by up to 6 -fold to 10 fold [39-41]. This expected underestimate of suicidal behavior has led us to focus our initial investigation, reported here, upon suicide deaths. Similarly, the V-code diagnosis of suicidal ideation we used to assess the potential for residual confounding (Table 5) likely captures only a small fraction of suicidal ideation. However, use of these codes was intended only as an aid to assess the potential presence and direction of residual confounding. For this purpose, diagnoses of suicidal ideation, even if infrequently coded, can provide valuable information, as has been the case in other studies [42].

Propensity score methods may also potentially inadvertently amplify any remaining confounding [23-26]. As

Table 5 Presence of V-code (62.84) denoting suicidal ideation in the $\mathbf{3 0}$ days prior to lithium or valproate initiation (2005-2008)

\begin{tabular}{lcccc}
\hline $\begin{array}{l}\text { Patient } \\
\text { characteristic }\end{array}$ & $\begin{array}{l}\text { Patients } \\
\text { initiating } \\
\text { lithium }\end{array}$ & $\begin{array}{l}\text { Patients } \\
\text { initiating } \\
\text { valproate }\end{array}$ & $\begin{array}{l}\text { Odds ratio } \\
\mathbf{( 9 5 \% ~ C l )}\end{array}$ & P value \\
\hline Suicidal Ideation & 305 & 237 & $1.30(1.09-1.54)$ & 0.003 \\
No Suicidal Ideation & 9478 & 9391 & & \\
\hline
\end{tabular}

pointed out above, such confounding could result from unmeasured differences in mental illness severity or in suicidal risks factors such as suicidal thinking, impulses, or intent. Such amplification is exacerbated if variables are included that are substantially associated with treatment (i.e., lithium or valproate initiation) but not outcome (i.e., suicide death) $[25,26]$. How much of a bias is typically produced is controversial $[25,43]$. Nevertheless, the differences between treatment groups in diagnosed suicidal ideation at baseline suggests some unaddressed confounding may remain in this study, and our particular implementation of propensity score matching included extensive variables in some domains (e.g., medical diagnoses) in which only a subset of variables may have been strongly related to suicide risk. (Harris and Barraclough, however, found that $90 \%$ of the medical diagnoses they reviewed were significantly associated with suicide death risk [44]). To reduce the potential for amplification of residual confounding, we actively evaluated the plausibility of confounding for those covariates with particularly substantial associations with treatment. Furthermore, a sensitivity analysis targeting this concern by removing a large number of covariates with the weakest apparent associations with suicide death from the propensity score produced only modest effect estimate changes (Additional file 1 : Appendix 7). Most importantly, the direction of change in the 0-365 day effect estimates from the unmatched $(\mathrm{OR}=1.45)$ to the matched sample $(\mathrm{cOR}=1.22)$ strongly suggests that overall confounding was most likely reduced by the propensity score matching, not amplified (Additional file 1: Appendix 6B). Therefore, any 
amplification of residual confounding appears to be sufficiently minor that the propensity score methodology still produced an important reduction in overall confounding. When comparing this study to other studies, however, it is important to note that amplification of residual confounding could have potentially enhanced, to at least a slight degree, an apparent bias in this study against observing a protective association between lithium treatment and suicide death.

\section{Generalizability, possible concordance with other recent studies, and potential "two-sided" benefit/risk aspects accompanying lithium initiation}

Generalizability of this study's findings to non-VHA patients, to patients with the excluded medical conditions (e.g., cancer, head injury, or seizures), to cohorts with differing rates of treatment discontinuation, or to patients that are treated for longer than one year is uncertain. Nevertheless, our findings generally agree with recent studies. With one exception [45], recent nonrandomized studies of suicide or suicidal behavior risk have observed nonsignificant (and typically modest) differences between lithium and valproate specifically, or lithium and anticonvulsants in general [34,36,46-49]. Recently, a small but methodologically-rigorous trial focused on suicidal behavior prevention [50] observed only nonsignificant differences in suicidal behavior between lithium and valproate. Results from this trial (involving 2.5 years of follow-up) and the BALANCE trial [51] (involving 2 years of follow-up) were combined in the recent randomized trial meta-analysis [8], which estimated that lithium treatment was associated with a nonsignificant reduction in nonfatal suicidal behavior compared to valproate (OR $0.64,95 \%$ CI $0.30-1.36, \mathrm{p}=0.24)$. Thus, the study reported here and the recent trials have both observed nonsignificant intent-to-treat differences between lithium and valproate in suicide death or suicidal behavior. The central estimate for lithium's effect size, however, did differ in direction between this study (nonsignificantly increased risk of suicide death) and the two trials (nonsignificantly decreased risk of suicidal behavior). This difference might simply be due to chance, residual confounding (possibly augmented by residual confounding amplification), differences in follow-up time (one year versus 2-2.5 years), or differences in outcome (suicide death versus suicidal behavior). However, this difference could also reflect a "two-sided" nature to lithium's association with the risk of suicide death/suicidal behavior. That is, some degree of decreased suicide/suicidal behavior may be associated with active lithium treatment (thus contributing more greatly to the intent-to-treat estimates from the trials, which had much higher treatment persistence rates), combined with some degree of increased risk associated with lithium discontinuation (which would thus contribute more greatly to the intent-to-treat estimates in our study). A possible "two-sided" association between lithium and the risk of suicide death would be also consistent with the significant differences in baseline suicidal ideation diagnoses between the treatment groups observed in this study (suggesting some residual confounding and thus a greater benefit to active lithium treatment than indicated) and the timing of the emergence of significant risks after lithium discontinuation (suggesting risks associated with discontinuation itself) (Additional file 1: Appendix 6D).

We suspect, although this supposition is inherently somewhat speculative, that the most likely interpretation of our findings includes both phenomena: some genuine association between lithium discontinuation and a short-term increase in the risk of suicide death (compared to valproate discontinuation), along with some residual confounding biasing against lithium. (This residual confounding would imply that active lithium treatment was associated with a larger decrease in suicide risk than estimated in this study). This interpretation would imply that it is difficult to determine whether initiation of lithium in our VHA cohort was associated with a net reduction or increase in suicide risk over the first year of treatment. Our data does suggest, however, that the overall balance of suicide-related risks and benefits from lithium initiation might be increased if greater adherence to initial lithium treatment could be achieved. Research investigating how different health systems could achieve this goal should be a high priority. Possible options include group psychoeducation, which is supported by two clinical trials $[52,53]$. One of these trials included psychoeducation with other treatment enhancements including detailed illness and treatment histories for each patient, follow-up within 2 weeks of hospital discharge, and a post-discharge "settling in" group [52]. A recent review identified five evidence-based strategies to boost mood stabilizer adherence, including psychoeducational, cognitive-behavioral, interpersonal, and family therapy approaches, as well as systematic care models [54].

\section{Clinical implications of potential discontinuation-associated risks}

Our findings clearly indicate a need for further research of lithium's association with suicide death or suicidal behavior (Additional file 1: Appendix 8). Until such research resolves the degree to which the increased risks of suicide death observed in patients discontinuing lithium relate specifically to lithium discontinuation (rather than confounding), prudence suggests patient and provider education about the possible risks of treatment discontinuation and close monitoring of patients discontinuing lithium (and potentially valproate [36]) when feasible. Such monitoring is already recommended to limit mood episode recurrences [55]. As discussed above, healthcare systems, 
providers, and patients should also strive to maximize persistence with lithium treatment once initiated. Finally, when discontinuation does occur, there may be value to gradually discontinuing lithium when appropriate, given that gradual discontinuation has been observed to substantially reduce the risk of mood episode relapse [56,57].

These recommendations concerning the need to minimize lithium and valproate discontinuation, and any risks resulting from this discontinuation, may have relevance well beyond the VHA. The substantial rates of lithium and valproate discontinuation observed here (median time to discontinuation of approximately 90 days) may not be particularly unusual. The observed rates of discontinuation fall within the range provided by the rates of lithium discontinuation reported for a U.S. health maintenance organization (median time to discontinuation of approximately 72 days) [58] and for patients with mood disorders in Denmark being managed primarily by general practitioners, rather than psychiatrists (median time to discontinuation of approximately 181 days) [59].

\section{Conclusions}

In summary, this study did not observe significant benefits for lithium in preventing suicide death compared to valproate among Veterans Health Administration patients over the first year of treatment. This study is notable, however, for high rates of discontinuation of both lithium and valproate, and for the finding of increased suicide risk among patients discontinuing lithium over 0-180 days. If such increased risk largely reflects confounding still persisting in the analysis, such confounding could conceal a clinically meaningful suicide preventative effect for lithium. Alternatively, some or all of the risk among patients discontinuing lithium could represent genuinely greater risks of suicide death related to lithium, compared to valproate, discontinuation. Until further research more fully clarifies the relationships between lithium treatment, discontinuation, and suicide death, patients initiating lithium should be educated concerning the possible risks associated with lithium discontinuation and the need to maximize persistence with lithium treatment, and be monitored closely after discontinuation if feasible. Further research incorporating intent-to-treat approaches is clearly needed, given the possible beneficial or hazardous effect sizes still compatible with this study's results, the pressing need for interventions against suicide, and the broad potential use of lithium.

\section{Additional file}

Additional file 1: Online Supplement for Smith et al., Suicide Risk in Veterans Health Administration Patients with Mental Health Diagnoses Initiating Lithium or Valproate: A Historical Prospective Cohort Study.

\section{Abbreviations}

Cl: Confidence interval; cOR: Conditional odds ratio; OR: Odds ratio; prn: Latin for pro re nata ("as the situation demands"), which is used in prescriptions to designate medications that are to be taken only as needed; VHA: Veterans Health Administration; ACE Inhibitor: Angiotensin-converting enzyme inhibitor; AMA: against medical advice; d: Days; D/C: Discharge;

Dep: Dependence; DX or Dx: Diagnosis; Dz: Disease; ER: Emergency room; Hosp: Hospitalization; Li: lithium; MH: Mental health; MAOIs: Monoamine oxidase inhibitors; NonMH: Nonmental health; NOS: Not otherwise specified;

NSAIDS: Non-steroidal anti-inflammatory medications; PTSD: Post-traumatic stress disorder; SNRI(s): Serotonin-norephinephrine reuptake inhibitor(s); SSRI(s): Serotonin-specific reuptake inhibitor(s); TBI: Traumatic brain injury; TCAs: Tricyclic antidepressants; VAL: valproate; w/: with; w/in: within; w/o: without.

\section{Competing interests}

The authors declare that they have no competing interests.

\section{Authors' contributions}

ES conceived of the study, managed the study, planned the analyses, and wrote the manuscript and online supplement. KA conducted the analyses, managed the database, provided input about alternative approaches, and helped revise the manuscript. HK provided statistical consultation, assisted in interpretation of the results and writing the Methods and Results sections, and helped revise the manuscript. DM provided mentorship of ES as part of his Career Development Award, provided specific guidance about propensity score and VHA large database methodology, and helped revise the manuscript. SE provided mentorship of ES as part of his Career Development Award, helped arrange for study initiation, provided extensive writing input, and helped revise the manuscript. CC provided additional statistical consultation and guidance about presentation of results and helped revise the manuscript. AK provided codes and guidance regarding some of the propensity score covariates and helped revise the manuscript. BS provided consultation and guidance about conducting extensive propensity scores and general methodology for large database medication studies and helped revise the manuscript. JM contributed expertise about the databases used, managed the analyses locally at Ann Arbor, and helped revise the manuscript. MV provided mentorship of ES as part of his Career Development Award, helped plan the study, provided expertise from her previous experience with nonrandomized medication studies in the VHA, participated in analytic decision-making, provided substantial input concerning the interpretation of the results, and helped revise the manuscript. All authors read and approved the final manuscript.

\section{Funding/Support}

This material is based upon work supported by the Department of Veterans Affairs, Veterans Health Administration, including the Office of Research and Development, Health Services Research and Development. Specifically, this work was financially supported by a Health Services Research and Development Service (HSR\&D) Career Development Award (CDA-09-216; E.G.S.), and by funding from the VHA HSRD Center for Healthcare Organization and Implementation Research, and by technical and programming support from the VHA Serious Mental Illness Treatment, Resource, and Evaluation Center, Ann Arbor, Michigan. Databases were constructed in part through funding from VHA HSR\&D MRP 03-320 and the VHA Serious Mental IIIness Treatment, Resource, and Evaluation Center. The views expressed in this article are those of the authors and do not necessarily reflect the position or policy of the Department of Veterans Affairs or the United States government. The research reported in this manuscript served as partial fulfillment of the requirements for Dr. Smith's Ph.D. thesis.

\section{Other contributions}

The authors wish to sincerely thank Dr. Matthew Miller of the Harvard School of Public Health for his suggestion to examine suicidal ideation diagnoses codes as one approach to making inferences about potential remaining confounding, and Dr. Amy Bohnert of the University of Michigan Medical School for providing the detailed substance abuse diagnoses codes.

\section{Author details}

'Department of Veterans Affairs, Health Services Research \& Development (HSR\&D) Center for Healthcare Organization and Implementation Research (CHOIR), MD-152, ENRM VAMC, 200 Springs Road, Bedford, MA 01730, USA. 
${ }^{2}$ Department of Psychiatry, University of Massachusetts Medical School, Worcester, MA, USA. ${ }^{3}$ Center for Clinical Management Research, Department of Veterans Affairs, Ann Arbor, MI, USA. ${ }^{4}$ Serious Mental Illness Treatment Resource and Evaluation Center, Department of Veterans Affairs, Ann Arbor, MI, USA. ${ }^{5}$ Center for Statistical Consultation and Research, University of Michigan, Ann Arbor, MI, USA. ${ }^{6}$ Department of Health Policy and Management, Boston University School of Public Health, Boston, MA, USA. ${ }^{7}$ Quality Enhancement Research Initiative (QUERI), Department of Veterans Affairs, Washington, DC, USA. ${ }^{8}$ Department of Psychiatry, University of Michigan Medical School, Ann Arbor, USA. 'VA IDEAS2.0 Center, Department of Veterans Affairs, Salt Lake City, UT, USA. ${ }^{10}$ Department of Internal Medicine, University of Utah, Salt Lake City, UT, USA.

Received: 3 July 2014 Accepted: 10 December 2014

Published online: 17 December 2014

\section{References}

1. World Health Organization: Preventing suicide, a global imperative. Geneva, Switzerland: World Health Organzation; 2014. [http://apps.who.int/ iris/bitstream/10665/131056/1/9789241564779_eng.pdf?ua=1]

2. Boehmer TK, Flanders WD, McGeehin MA, Boyle C, Barrett DH: Postservice mortality in Vietnam veterans: 30-year follow-up. Arch Intern Med 2004, 164(17):1908-1916.

3. Ilgen MA, McCarthy JF, Ignacio RV, Bohnert AS, Valenstein M, Blow FC, Katz IR: Psychopathology, Iraq and Afghanistan Service, and Suicide Among Veterans Health Administration Patients. J Consult Clin Psychol 2012, 80(3):323-30.

4. Blow FC, Bohnert AS, Ilgen MA, Ignacio R, McCarthy JF, Valenstein MM, Knox KL: Suicide mortality among patients treated by the Veterans Health Administration from 2000 to 2007. Am J Public Health 2012, 102(Suppl 1):S98-104.

5. Baldessarini RJ, Tondo L, Davis P, Pompili M, Goodwin FK, Hennen J: Decreased risk of suicides and attempts during long-term lithium treatment: a meta-analytic review. Bipolar Disord 2006, 8(5 Pt 2):625-639.

6. Goodwin FK, Fireman B, Simon GE, Hunkeler EM, Lee J, Revicki D: Suicide risk in bipolar disorder during treatment with lithium and divalproex. JAMA 2003, 290(11):1467-1473.

7. Baldessarini RJ, Tondo L: Lithium and suicidal risk. Bipolar Disord 2008, 10(1):114-115.

8. Cipriani A, Hawton K, Stockton S, Geddes JR: Lithium in the prevention of suicide in mood disorders: updated systematic review and meta-analysis. BMJ 2013, 346:33646.

9. Lauterbach E, Felber W, Muller-Oerlinghausen B, Ahrens B, Bronisch T, Meyer T, Kilb B, Lewitzka U, Hawellek B, Quante A, Richter K, Broocks A, Hohagen F: Adjunctive lithium treatment in the prevention of suicidal behaviour in depressive disorders: a randomised, placebo-controlled, 1-year trial. Acta Psychiatr Scand 2008, 118(6):469-479.

10. Ernst CL, Goldberg JF: Antisuicide properties of psychotropic drugs: a critical review. Harv Rev Psychiatry 2004, 12(1):14-41.

11. Nilsson A: Lithium therapy and suicide risk. J Clin Psychiatry 1999, 60(Suppl 2):85-88. discussion 111-116.

12. Baldessarini RJ, Tondo L, Hennen J: Effects of lithium treatment and its discontinuation on suicidal behavior in bipolar manic-depressive disorders. J Clin Psychiatry 1999, 60(Suppl 2):77-84. discussion 111-116.

13. Tondo L, Jamison KR, Baldessarini RJ: Effect of lithium maintenance on suicidal behavior in major mood disorders. Ann N Y Acad Sci 1997, 836:339-351.

14. American Psychiatric Association: Practice guideline for the treatment of patients with bipolar disorder (revision). Am J Psychiatry 2002, 159(4 Suppl 4):1-50.

15. Austin PC, Grootendorst P, Anderson GM: A comparison of the ability of different propensity score models to balance measured variables between treated and untreated subjects: a Monte Carlo study. Stat Med 2007, 26(4):734-753

16. Schneeweiss S, Rassen JA, Glynn RJ, Avorn J, Mogun H, Brookhart MA: High-dimensional propensity score adjustment in studies of treatment effects using health care claims data. Epidemiology 2009, 20(4):512-522.

17. Hernan MA, Robins JM: Authors' response, part I: observational studies analyzed like randomized experiments: best of both worlds. Epidemiology 2008, 19(6):789-792
18. Blow FC, Valenstein M, Austin K, Khanuja K, McCarthy JF: Specialty Care for Veterans with Depression in the VHA: 2002 National Depression Registry Report. In. Ann Arbor, MI: VA National Serious Mental Illness Treatment Research \& Evaluation Center (SMITREC), VHA Health Services Research \& Development; 2003.

19. Guzzetta F, Tondo L, Centorrino F, Baldessarini RJ: Lithium treatment reduces suicide risk in recurrent major depressive disorder. J Clin Psychiatry 2007, 68(3):380-383.

20. Cowper DC, Kubal JD, Maynard C, Hynes DM: A primer and comparative review of major US mortality databases. Ann Epidemiol 2002, 12(7):462-468.

21. McCarthy JF, Valenstein M, Kim HM, Ilgen M, Zivin K, Blow FC: Suicide mortality among patients receiving care in the veterans health administration health system. Am J Epidemiol 2009, 169(8):1033-1038.

22. Patorno E, Bohn RL, Wahl PM, Avorn J, Patrick AR, Liu J, Schneeweiss S: Anticonvulsant medications and the risk of suicide, attempted suicide, or violent death. JAMA 2010, 303(14):1401-1409.

23. Bhattacharya J, Vogt W: Do instrumental variables belong in propensity scores? In NBER Technical Working Paper no 343. Cambridge, MA: National Bureau of Economic Research; 2007 [http://www.nber.org/papers/t0343].

24. Wooldridge J: Should instrumental variables be used as matching variables? East Lansing, Ml: Michigan State University; 2009 [http://econ.msu.edu/ faculty/wooldridge/docs/treat1 r6.pdf].

25. Pearl J: Invited commentary: understanding bias amplification. Am J Epidemiol 2011, 174(11):1223-1227. discussion pg 1228-1229.

26. Brooks JM, Ohsfeldt RL: Squeezing the balloon: propensity scores and unmeasured covariate balance. Health Serv Res 2013, 48(4):1487-501.

27. Austin PC: Some methods of propensity-score matching had superior performance to others: results of an empirical investigation and Monte Carlo simulations. Biom J 2009, 51(1):171-184.

28. Faries DE, Leon AC, Haro JM, Obenchain RL: Analysis of Observational Health Care Data Using SAS. Cary, NC: SAS Institute; 2010.

29. Cipriani A, Pretty H, Hawton K, Geddes JR: Lithium in the prevention of suicidal behavior and all-cause mortality in patients with mood disorders: a systematic review of randomized trials. Am J Psychiatry 2005, 162(10):1805-1819.

30. Ahrens B, Muller-Oerlinghausen B, Grof P: Length of lithium treatment needed to eliminate the high mortality of affective disorders. Br J Psychiatry Suppl 1993, 21:27-29.

31. Ahrens B, Grof P, Moller HJ, Muller-Oerlinghausen B, Wolf T: Extended survival of patients on long-term lithium treatment. Can J Psychiatry 1995, 40(5):241-246

32. Muller-Oerlinghausen B, Wolf T, Ahrens B, Schou M, Grof E, Grof P, Lenz G, Simhandl C, Thau K, Wolf R: Mortality during initial and during later lithium treatment. A collaborative study by the International Group for the Study of Lithium-treated Patients. Acta Psychiatr Scand 1994, 90(4):295-297

33. Muller-Oerlinghausen B, Muser-Causemann B, Volk J: Suicides and parasuicides in a high-risk patient group on and off lithium long-term medication. J Affect Disord 1992, 25(4):261-269.

34. Yerevanian Bl, Ralph JK, Mintz J: Bipolar pharmacotherapy and suicidal behavior. Part I: Lithium, divalproex and carbamazepine. J Affect Disord 2007, 103:5-11.

35. Cooper WO, Habel LA, Sox CM, Chan KA, Arbogast PG, Cheetham TC, Murray KT, Quinn VP, Stein CM, Callahan ST, Fireman BH, Fish FA, Kirshner HS, O'Duffy A, Connell FA, Ray WA: ADHD drugs and serious cardiovascular events in children and young adults. N Engl J Med 2011, 365(20):1896-1904.

36. Yerevanian $B I$, Koek RJ, Mintz J: Lithium, anticonvulsants and suicidal behavior in bipolar disorder. J Affect Disord 2003, 73(3):223-228.

37. Yerevanian BI, Koek RJ, Mintz J, Akiskal HS: Bipolar pharmacotherapy and suicidal behavior Part 2. The impact of antidepressants. J Affect Disord 2007, 103(1-3):13-21.

38. Yerevanian BI, Koek RJ, Mintz J: Bipolar pharmacotherapy and suicidal behavior Part 3: impact of antipsychotics. J Affect Disord 2007, 103(1-3):23-28.

39. Patrick AR, Miller M, Barber CW, Wang PS, Canning CF, Schneeweiss S: Identification of hospitalizations for intentional self-harm when E-codes are incompletely recorded. Pharmacoepidemiol Drug Saf 2010, 19(12):1263-1275.

40. Hammond KW, Laundry RJ, O'Leary TM, Jones WP: Use of text search to effectively identify lifetime prevalence of suicide attempts among veterans. Proceedings Of The 2013 46th Annual Hawaii International 
Conference On System Sciences (HICSS 2013), Jan 7-10, 2013, Computer Society Press, 2013, pp. 2676-2683 (ISBN: 978-1-4673-5933-7); available at http://www.computer.org/csdl/proceedings/hicss/2013/4892/00/4892c676. pdf.

41. Kim H, Smith E, Stano C, Ganoczy D, Zivin K, Walters H, Valenstein M: Validation of key behaviourally based mental health diagnoses in administrative data: suicide attempt, alcohol abuse, illicit drug abuse and tobacco use. BMC Health Serv Res 2012, 12(1):18.

42. Miller M, Swanson SA, Azrael D, Pate V, Sturmer T: Antidepressant dose, age, and the risk of deliberate self-harm. JAMA Intern Med 2014, 174(6):899-909.

43. Myers JA, Rassen JA, Gagne JJ, Huybrechts KF, Schneeweiss S, Rothman KJ, Joffe MM, Glynn RJ: Effects of adjusting for instrumental variables on bias and precision of effect estimates. Am J Epidemiol 2011, 174(11):1213-1222.

44. Harris EC, Barraclough B: Suicide as an outcome for mental disorders. A meta-analysis. Br J Psychiatry 1997, 170:205-228.

45. Koek RJ, Yerevanian BI, Mintz J: Subtypes of antipsychotics and suicidal behavior in bipolar disorder. J Affect Disord 2012, 143(1-3):27-33.

46. Sondergard L, Lopez AG, Andersen PK, Kessing LV: Mood-stabilizing pharmacological treatment in bipolar disorders and risk of suicide. Bipolar Disord 2008, 10(1):87-94.

47. Smith EG, Sondergard L, Lopez AG, Andersen PK, Kessing LV: Association between consistent purchase of anticonvulsants or lithium and suicide risk: A longitudinal cohort study from Denmark, 1995-2001. J Affect Disord 2009, 117(3):162-7.

48. Collins JC, MCFarland BH: Divalproex, lithium and suicide among Medicaid patients with bipolar disorder. J Affect Disord 2008, 107(1-3):23-28.

49. Gibbons RD, Hur K, Brown CH, Mann JJ: Relationship between antiepileptic drugs and suicide attempts in patients with bipolar disorder. Arch Gen Psychiatry 2009, 66(12):1354-1360.

50. Oquendo MA, Galfalvy HC, Currier D, Grunebaum MF, Sher L, Sullivan GM, Burke AK, Harkavy-Friedman J, Sublette ME, Parsey RV, Mann JJ: Treatment of suicide attempters with bipolar disorder: a randomized clinical trial comparing lithium and valproate in the prevention of suicidal behavior. Am J Psychiatry 2011, 168(10):1050-1056.

51. Geddes JR, Goodwin GM, Rendell J, Azorin JM, Cipriani A, Ostacher MJ, Morriss $\mathrm{R}$, Alder N, Juszczak E: Lithium plus valproate combination therapy versus monotherapy for relapse prevention in bipolar I disorder (BALANCE): a randomised open-label trial. Lancet 2010, 375(9712):385-395.

52. Kessing LV, Hansen HV, Hvenegaard A, Christensen EM, Dam H, Gluud C, Wetterslev J: Treatment in a specialised out-patient mood disorder clinic v. standard out-patient treatment in the early course of bipolar disorder: randomised clinical trial. Br J Psychiatry 2013, 202(3):212-219.

53. Colom F, Vieta E, Sanchez-Moreno J, Palomino-Otiniano R, Reinares M Goikolea JM, Benabarre A, Martinez-Aran A: Group psychoeducation for stabilised bipolar disorders: 5-year outcome of a randomised clinical trial. Br J Psychiatry 2009, 194(3):260-265.

54. Lolich M, Vazquez GH, Alvarez LM, Tamayo JM: Psychosocial interventions in bipolar disorder: a review. Actas Esp Psiquiatr 2012, 40(2):84-92.

55. Goodwin GM: Evidence-based guidelines for treating bipolar disorder: revised second edition-recommendations from the British Association for Psychopharmacology. J Psychopharmacol (Oxf) 2009, 23(4):346-388.

56. Faedda GL, Tondo L, Baldessarini RJ, Suppes T, Tohen M: Outcome after rapid vs gradual discontinuation of lithium treatment in bipolar disorders. Arch Gen Psychiatry 1993, 50(6):448-455.

57. Baldessarini RJ, Tondo L, Faedda GL, Suppes TR, Floris G, Rudas N: Effects of the rate of discontinuing lithium maintenance treatment in bipolar disorders. J Clin Psychiatry 1996, 57(10):441-448.

58. Johnson RE, McFarland BH: Lithium use and discontinuation in a health maintenance organization. Am J Psychiatry 1996, 153(8):993-1000.

59. Kessing LV, Sondergard L, Kvist K, Andersen PK: Adherence to lithium in naturalistic settings: results from a nationwide pharmacoepidemiological study. Bipolar Disord 2007, 9(7):730-736.

\section{Submit your next manuscript to BioMed Central and take full advantage of:}

- Convenient online submission

- Thorough peer review

- No space constraints or color figure charges

- Immediate publication on acceptance

- Inclusion in PubMed, CAS, Scopus and Google Scholar

- Research which is freely available for redistribution

Submit your manuscript at www.biomedcentral.com/submit 